\section{RMD Open}

Rheumatic \&

Musculoskeletal Diseases

\title{
Stroke in systemic lupus erythematosus: a meta-analysis of population-based cohort studies
}

\author{
Marie Holmqvist, ${ }^{1}$ Julia F Simard, ${ }^{1,2}$ Kjell Asplund, ${ }^{3}$ Elizabeth V Arkema ${ }^{1}$
}

To cite: Holmqvist $\mathrm{M}$, Simard JF, Asplund K, et al. Stroke in systemic lupus erythematosus: a metaanalysis of population-based cohort studies. RMD Open 2015;1:e000168.

doi:10.1136/rmdopen-2015000168

\section{- Prepublication history and additional material is available. To view please visit the journal (http://dx.doi.org/ 10.1136/rmdopen-2015- 000168).}

Received 11 August 2015 Revised 29 September 2015 Accepted 11 October 2015

\section{CrossMark}

${ }^{1}$ Clinical Epidemiology Unit, Department of Medicine Solna, Karolinska Institute, Stockholm, Sweden

${ }^{2}$ Division of Epidemiology, Department of Health Research \& Policy, Stanford School of Medicine, Stanford, California, USA

${ }^{3}$ Department of Public Health and Clinical Medicine, Umeå University, Umeå, Sweden

Correspondence to Dr Elizabeth V Arkema; Elizabeth.Arkema@ki.se

\section{ABSTRACT}

Previous studies of stroke in systemic lupus erythematosus (SLE) have had limited statistical power, combined stroke subtypes into composite outcomes, and lacked a reference population estimate. Therefore, we conducted a systematic review and meta-analysis of cohort studies to summarise the stroke subtypespecific risk in patients with SLE compared to the general population. A systematic search of MEDLINE and EMBASE was performed for cohort studies examining the risk of stroke in SLE and including a general population comparator. Random effects models were used to pool the risk ratio (RR) for stroke. Subgroup analyses were carried out to investigate potential sources of heterogeneity. 10 studies were included which reported RRs for overall stroke $(n=5)$, ischaemic stroke $(n=6)$, intracerebral haemorrhage $(n=3)$ and subarachnoid haemorrhage $(n=3)$. The pooled RR for overall stroke was $2.53(95 \% \mathrm{Cl} 1.96$ to $3.26)$, ischaemic stroke $2.10(95 \% \mathrm{Cl} 1.68$ to 2.62$)$, intracerebral haemorrhage $2.72(95 \% \mathrm{Cl} 2.15$ to 3.44$)$ and subarachnoid haemorrhage $3.85(95 \% \mathrm{Cl} 3.20$ to 4.64). Significant heterogeneity among studies for ischaemic stroke was detected ( $p=0.002)$. Relative risk of stroke was highest among individuals younger than 50 years of age. Individuals with SLE have a twofold higher risk of ischaemic stroke, a threefold higher risk of intracerebral haemorrhage, and an almost fourfold higher risk of subarachnoid haemorrhage compared to the general population. Future studies should focus on whether comorbidity and disease flares are related to stroke, when individuals are at the highest risk, and how the targeting of specific groups of patients with SLE may reduce this risk.

\section{INTRODUCTION}

Systemic lupus erythematosus (SLE) is a chronic systemic inflammatory disease that is associated with an increased risk of cerebrovascular events, which account for $10-15 \%$ of deaths in SLE. ${ }^{1}$ Individuals with SLE have a lower rate of survival after stroke compared to the general population, but it is unclear whether this is due to the increased rate of

\section{Key messages}

What is already known about this subject?

- Previous studies have indicated that individuals with systemic lupus erythematosus (SLE) have an increased risk of cerebrovascular events, but it remains unclear to what extent the risk is increased compared to the general population.

What does this study add?

- Individuals with SLE have a twofold higher risk of ischaemic stroke, a threefold higher risk of intracerebral haemorrhage, and an almost fourfold higher risk of subarachnoid haemorrhage.

- Our results confirm that individuals with SLE are at a higher risk of stroke than the general population, regardless of the type of stroke.

How might this impact on clinical practice?

- Awareness of the increased risk of stroke in patients with SLE may help to prevent stroke and/or minimise damage and disability due to stroke if stroke is identified early.

stroke or whether stroke is more severe in SLE. ${ }^{2}$ Previous studies evaluating the association between SLE and stroke have used cross-sectional and case-control designs, which may only include individuals who survived a stroke to be included in the study. ${ }^{3-5}$ Some investigations of small clinical cohorts did not compare rates to a general population comparator. ${ }^{6} 7$ Other studies included stroke in a composite end point with other cardiovascular diseases, ${ }^{89}$ increasing the statistical power but possibly diluting the observed association due to different underlying pathological processes. There is sparse information on intracerebral and subarachnoid haemorrhage that have a higher case fatality rate than ischaemic stroke (25-35\% vs $13-23 \%$, respectively). ${ }^{10}$ In addition to being associated with a higher mortality, haemorrhagic stroke occurs at a younger age, which leads to a higher risk of long-term 
morbidity. Given the low numbers in individual studies, a meta-analysis of combined studies is warranted.

It is necessary to better understand the risk of stroke in SLE and how it differs by patient characteristics in comparison to individuals without SLE. This understanding may help to identify methods of prevention in this at-risk group and show how SLE plays a role in the development of stroke. We, therefore, conducted a systematic review and meta-analysis to estimate the risk of stroke in patients with SLE compared to the general population.

\section{METHODS}

\section{Search strategies}

We followed the PRISMA guidelines for conducting and reporting systematic reviews and meta-analyses. ${ }^{11}$ The MEDLINE (PubMed 1950 to June 2015) and EMBASE (1980 to June 2015) databases were searched by MH and EA to identify published studies and reviews of stroke in SLE. The search terms systemic lupus erythematosus and stroke were used in combination with no language or year restrictions (see online supplementary file). The authors also searched the reference lists of key articles as well as the abstracts presented at the American College of Rheumatology and European League Against Rheumatism conferences 2012-2014. For articles where stroke estimates were combined with other outcomes, the authors of the original publication were contacted in order to retrieve stroke-specific estimates.

To minimise the likelihood of bias which commonly affects cross-sectional and case-control studies, we included cohort studies only. We selected cohort studies that met the following inclusion criteria: (1) predefined SLE criteria; (2) predefined stroke criteria for incident event (ischaemic stroke, intracerebral haemorrhage or subarachnoid haemorrhage); (3) HR, rate ratio or risk ratio (RR) estimates with $95 \%$ CI or $\mathrm{p}$ value and (4) a general population comparison group. A general population comparator was required so that estimates would reflect the relative risk of stroke associated with SLE compared to non-SLE, and account for varying rates of stroke across populations.

\section{Data extraction}

Two researchers (MH and EA) independently assessed studies for eligibility and extracted data on year of publication, type of study, source of the sample, SLE definition (American College of Rheumatology (ACR) criteria, medical record review, International Classification of Diseases (ICD) 9710 or ICD-10 M32), sample size, enrolment period, SLE duration at study entry, mean time of follow-up, reference group, stroke definition (ICD-9 430-437 or ICD-10 I60-I64, medical record review) and number of stroke events overall and by stroke subtype, if available. Any differences among the two authors were discussed until consensus was reached. When necessary, an additional researcher (JS) was contacted for extended discussions.

\section{Quality of included studies}

We assessed the following features which may introduce bias in cohort studies: the source of the patient sample (population-based, clinic-based), cohort type (inception, non-inception), SLE definition (medical record review, ICD code only), ascertainment of stroke outcome (medical record review, ICD code only), exclusion of prevalent stroke at baseline, and adjustment for confounders. In addition, the Newcastle-Ottawa scale was used to evaluate the quality of the studies. ${ }^{12}$

\section{Statistical analysis}

HRs and rate ratios were considered equivalent estimates of RRs and referred to as such throughout. We used random effects models to calculate the pooled RR and 95\% CI for each stroke type reported (overall stroke, ischaemic stroke, intracerebral haemorrhage, subarachnoid haemorrhage). The pooled RR represents a summary estimate of the increased risk of stroke in individuals with SLE compared to those without SLE, weighted by a factor that is influenced by the sample size of each study. Calculations were performed on the $\log$ of the RR from the individual studies, and the resulting pooled values were then transformed back to the RR scale. We tested for heterogeneity using the $Q$ statistic (considered statistically significant if $\mathrm{p}<0.10$ ), and by calculating the $\mathrm{I}^{2}$ and $\mathrm{p}$ value. $\mathrm{I}^{2}>50 \%$ indicates that a high percentage of the total variance in effect estimates is due to heterogeneity rather than chance. All analyses were conducted using Stata statistical software V.13.0.

If the same data source was used in multiple studies, the RR estimate from the study with the highest quality was used in the pooled analyses. In sensitivity analyses, we included studies that were excluded on this basis to determine if this affected results. Subgroup analyses were carried out to investigate potential sources of heterogeneity. Studies were stratified based on study region and characteristics related to study quality (exclusion of previous strokes at baseline, incident SLE at baseline, adjustment for confounders), as well as age and sex if available. Robustness of the results was evaluated by examining whether the pooled estimates were influenced by the removal of each individual study. To detect the presence of publication bias or small-study effect (the tendency for effect estimates in small studies to differ from those in larger studies), we evaluated the symmetry of funnel plots for each stroke outcome. In addition, Egger's test was used to examine potential publication bias with a quantitative test statistic (considered significant if $\mathrm{p}<0.05)$.

\section{RESULTS}

\section{Literature search}

We identified 10 studies using the predefined search terms (including one abstract ${ }^{13}$ ) (figure 1)..$^{13-21}$ The majority of studies were excluded because these were either case reports or did not include a general 


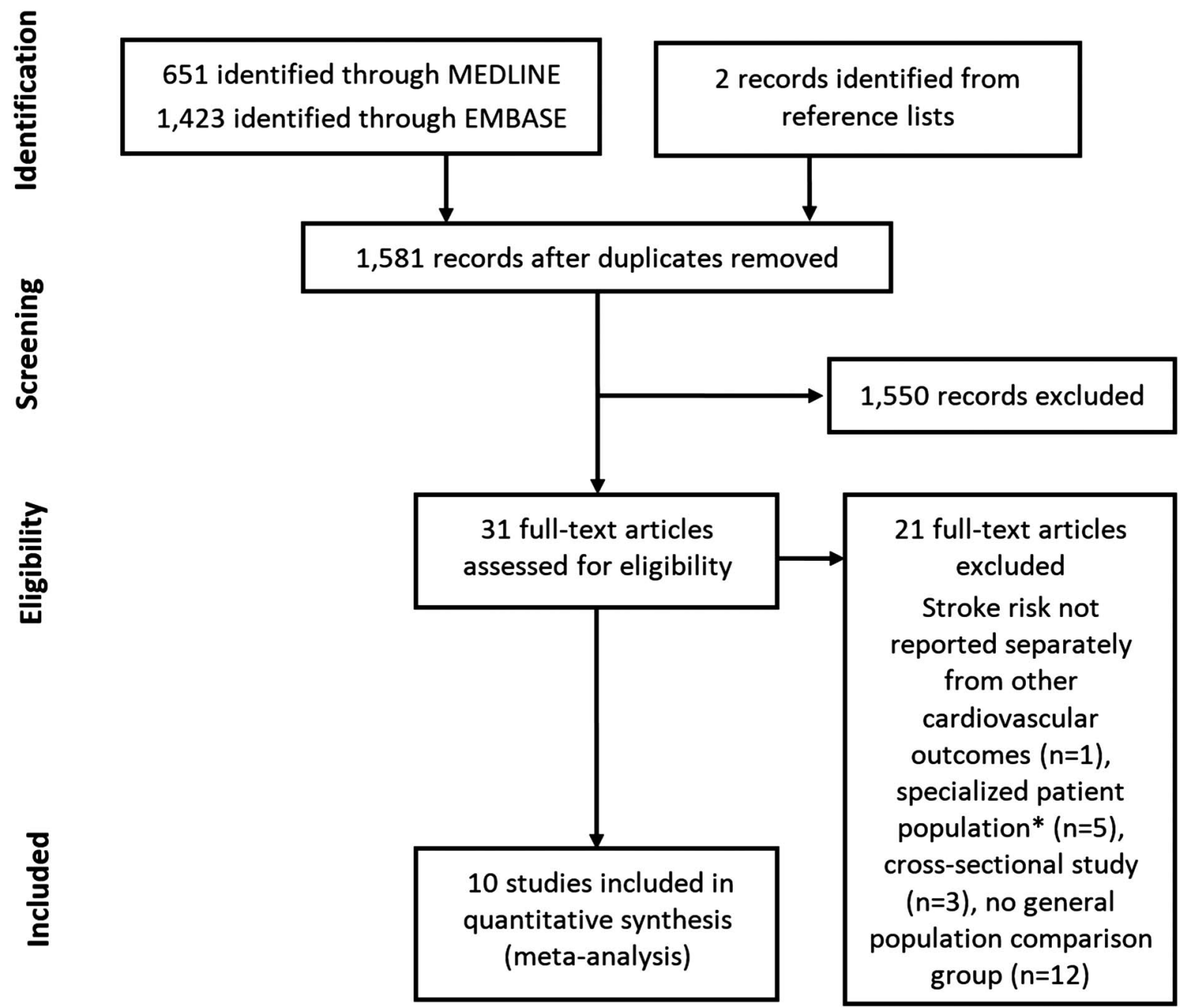

Figure 1 Flow diagram of the literature search process, including exclusions and reasons for exclusions. *Population of pregnant women $(n=2)$, asymptomatic antiphospholipid carriers $(n=1)$, surgical patients $(n=1)$, patients with end-stage renal disease $(n=1)$.

population comparator. Two studies combined stroke, myocardial infarction and coronary artery disease in a composite end point, ${ }^{89}$ and the authors from one study provided us with the stroke-specific estimate. ${ }^{9}$ Five studies were excluded because these examined stroke in a specialised instead of general patient populations (pregnant women, ${ }^{22} 23$ asymptomatic antiphospholipid antibody carriers, ${ }^{24}$ surgical patients ${ }^{25}$ and patients with end-stage renal disease ${ }^{26}$ ). Three cross-sectional studies were excluded. ${ }^{3-5}$ Two studies used the Framingham risk score to estimate the expected risk of stroke in non-SLE and compared this to clinical cohorts of SLE; these were, therefore, excluded due to the lack of a population comparator. ${ }^{27} 28$

\section{Study characteristics}

The characteristics of the included studies are displayed in table 1. Five studies estimated the RR for overall stroke, not specifying type of stroke. ${ }^{9}{ }^{16-18}{ }^{20}$ Three studies estimated the RR for intracerebral haemorrhage, ${ }^{18} 2021$ one of which combined intracerebral and subarachnoid haemorrhage. ${ }^{18}$ Three examined subarachnoid haemorrhage separately. ${ }^{14}{ }^{19}{ }^{20}$ Six studies presented estimates for ischaemic stroke, ${ }^{13} 1517182021$ one of which included the ICD-9 code for subarachnoid haemorrhage (ICD-9 430) in the ischaemic stroke outcome. ${ }^{17}$ Liou et al investigated the risk of intracerebral haemorrhage; they did not give the number of events or subtype-specific HR, and only reported that the finding was non-significant. There were five studies from Asia (four from Taiwan ${ }^{14} \quad{ }^{15} \quad 17 \quad 20$ and one from China ${ }^{18}$ ), three from Europe (one from the $\mathrm{UK}^{19}$ and two from Sweden ${ }^{9}{ }^{21}$ ) and two from North America (one each from Canada ${ }^{13}$ and the $\mathrm{USA}^{16}$ ). All of the studies were published in the last 6 years and two studies had over 20 years of follow-up. ${ }^{16} 20$

Table 2 shows additional characteristics relating to the quality of each study. The majority of the studies were considered to be of sufficiently high quality; however, four studies did not report the duration of disease or included prevalent SLE at baseline, ${ }^{9} 17{ }^{17}{ }^{21}$ and two studies did not exclude individuals with a history of 
Table 1 Characteristics of the studies included in the meta-analysis to assess the risk of stroke associated with SLE

\begin{tabular}{|c|c|c|c|c|c|c|}
\hline $\begin{array}{l}\text { First author and year of } \\
\text { publication }\end{array}$ & $\begin{array}{l}\text { Study } \\
\text { period }\end{array}$ & Country & Data source(s) & $\begin{array}{l}\text { SLE } \\
\text { (n) }\end{array}$ & $\begin{array}{l}\text { Non-SLE } \\
\text { (n) }\end{array}$ & Stroke definitions used as outcomes* \\
\hline Agha, $2014^{13}$ & 1996-2010 & Canada & Medical Services Plan, British Columbia & 4972 & 49948 & Ischaemic stroke \\
\hline Bengtsson, $2012^{9}$ & 2001-2007 & Sweden & $\begin{array}{l}\text { N. Sweden Clinical Cohort, medical biobank of } \\
\text { N. Sweden, national inpatient register }\end{array}$ & 277 & 520 & Any stroke \\
\hline Chang, $2013^{14}$ & 2000-2006 & Taiwan & $\begin{array}{l}\text { Taiwan National Health Insurance Research } \\
\text { Database }\end{array}$ & 16967 & 16967 & Subarachnoid haemorrhage \\
\hline Chiu, $2012^{15}$ & 2000-2007 & Taiwan & $\begin{array}{l}\text { Taiwan National Health Insurance Research } \\
\text { Database }\end{array}$ & 11637 & 58185 & Ischaemic stroke \\
\hline Hak, $2009^{16}$ & 1976-2004 & USA & Nurses' Health Study & 148 & 119332 & Any stroke \\
\hline Liou, $2014^{17}$ & 2004-2007 & Taiwan & $\begin{array}{l}\text { Taiwan Longitudinal Health Insurance Database } \\
2005\end{array}$ & 2484 & 2484 & $\begin{array}{l}\text { Any stroke, ischaemic stroke and } \\
\text { intracerebral haemorrhage } \dagger\end{array}$ \\
\hline Mok, $2009^{18}$ & 1999-2007 & China & $\begin{array}{l}\text { Hospital-based SLE cohort and stroke events } \\
\text { admitted to the same hospital to obtain general } \\
\text { population rates from the hospital catchment area }\end{array}$ & 490 & $\begin{array}{l}\text { Not } \\
\text { reported }\end{array}$ & $\begin{array}{l}\text { Any stroke, ischaemic and haemorrhagic } \\
\text { stroke (intracerebral and subarachnoid } \\
\text { haemorrhage combined) }\end{array}$ \\
\hline Ramagopalan, $2013^{19}$ & 1999-2011 & UK & English national Hospital Episode Statistics & 25576 & $\approx 7600000$ & Subarachnoid haemorrhage \\
\hline Wang, $2012^{20}$ & 1997-2008 & Taiwan & $\begin{array}{l}\text { Taiwan National Health Insurance Research } \\
\text { Database }\end{array}$ & 13689 & 54756 & $\begin{array}{l}\text { Any stroke, ischaemic stroke, intracerebral } \\
\text { and subarachnoid haemorrhage }\end{array}$ \\
\hline Zöller, $2012^{21}$ & 1987-2008 & Sweden & $\begin{array}{l}\text { Swedish national inpatient register and total } \\
\text { population of Sweden as reference group }\end{array}$ & 4179 & $\begin{array}{l}\text { Not } \\
\text { reported }\end{array}$ & $\begin{array}{l}\text { Ischaemic stroke and intracerebral } \\
\text { haemorrhage }\end{array}$ \\
\hline
\end{tabular}


Table 2 Quality assessment of the studies included in the meta-analysis to assess the risk of stroke associated with SLE

\begin{tabular}{|c|c|c|c|c|c|c|c|}
\hline $\begin{array}{l}\text { First author } \\
\text { and year of } \\
\text { publication }\end{array}$ & $\begin{array}{l}\text { Source of } \\
\text { SLE } \\
\text { population }\end{array}$ & Ascertainment of SLE & $\begin{array}{l}\text { Incident or } \\
\text { prevalent SLE } \\
\text { at start of } \\
\text { follow-up }\end{array}$ & $\begin{array}{l}\text { Exclusion of } \\
\text { prevalent } \\
\text { stroke at start } \\
\text { of follow-up }\end{array}$ & Matching & $\begin{array}{l}\text { Confounders considered and } \\
\text { adjusted for }\end{array}$ & $\begin{array}{l}\text { Newcastle- } \\
\text { Ottawa Quality } \\
\text { Assessment } \\
\text { Scale }\end{array}$ \\
\hline Agha, $2014^{13}$ & $\begin{array}{l}\text { Population } \\
\text { based }\end{array}$ & $\begin{array}{l}\geq 2 I C D \text { codes in a } \\
\text { non-rheumatology unit or } \\
\geq 1 \text { ICD code in } \\
\text { rheumatology }\end{array}$ & $\begin{array}{l}\text { Incident } \\
\text { (5-year } \\
\text { washout) }\end{array}$ & Yes & $\begin{array}{l}\text { Birth year, sex, } \\
\text { calendar year }\end{array}$ & $\begin{array}{l}\text { Number of hospitalisations, } \\
\text { comorbidity, medications }\end{array}$ & 9 \\
\hline $\begin{array}{l}\text { Bengtsson, } \\
2012^{9}\end{array}$ & $\begin{array}{l}\text { Population } \\
\text { based }\end{array}$ & $\begin{array}{l}\text { Clinical cases, physician } \\
\text { diagnosis, ACR criteria } \geq 4\end{array}$ & Prevalent & No & Age, sex & Sex, year & 8 \\
\hline Chang, $2013^{14}$ & $\begin{array}{l}\text { Population } \\
\text { based }\end{array}$ & $\begin{array}{l}\text { ICD code, registered for } \\
\text { catastrophic illness }\end{array}$ & $\begin{array}{l}\text { Incident } \\
\text { (5-year } \\
\text { washout) }\end{array}$ & Yes & Age, sex & None & 7 \\
\hline Chiu, $2012^{15}$ & $\begin{array}{l}\text { Population } \\
\text { based }\end{array}$ & $\begin{array}{l}I C D \text { code in rheumatology, } \\
\text { registered for catastrophic } \\
\text { illness }\end{array}$ & $\begin{array}{l}\text { Incident } \\
\text { (3-year } \\
\text { washout) }\end{array}$ & Yes & $\begin{array}{l}\text { Age, sex, } \\
\text { comorbidities }\end{array}$ & Age, sex, comorbidity & 9 \\
\hline Hak, $2009^{16}$ & Cohort study & $\begin{array}{l}\text { Initially self-reported via } \\
\text { questionnaire with medical } \\
\text { record review of all cases, } \\
\text { ACR criteria } \geq 4\end{array}$ & Incident & Yes & None & $\begin{array}{l}\text { Age, comorbidity, parental history } \\
\text { of congestive heart disease, body } \\
\text { mass index, physical exercise, } \\
\text { smoking, alcohol, menopausal } \\
\text { status, hormone use, medications, } \\
\text { race }\end{array}$ & 9 \\
\hline Liou, $2014^{17}$ & $\begin{array}{l}\text { Population } \\
\text { based }\end{array}$ & $\begin{array}{l}\geq 15 \text { ICD codes in } \\
\text { rheumatology }\end{array}$ & Unclear & Yes & Age, sex & $\begin{array}{l}\text { Age, sex, comorbidity, } \\
\text { urbanisation }\end{array}$ & 9 \\
\hline Mok, $2009^{18}$ & $\begin{array}{l}\text { Hospital } \\
\text { based }\end{array}$ & $\begin{array}{l}\text { Clinical diagnosis, } \\
\text { ACR criteria } \geq 4\end{array}$ & Unclear & No & None & Unclear & 4 \\
\hline $\begin{array}{l}\text { Ramagopalan, } \\
2013^{19}\end{array}$ & $\begin{array}{l}\text { Population } \\
\text { based }\end{array}$ & $\begin{array}{l}\text { Any ICD code in hospital } \\
\text { day case care or inpatient } \\
\text { admission }\end{array}$ & $\begin{array}{l}\text { Incident and } \\
\text { prevalent }\end{array}$ & Yes & None & $\begin{array}{l}\text { Age, sex, time period, region, } \\
\text { socioeconomic status }\end{array}$ & 9 \\
\hline Wang, $2012^{20}$ & $\begin{array}{l}\text { Population } \\
\text { based }\end{array}$ & $\begin{array}{l}\text { ICD code from } \\
\text { rheumatologist visits and } \\
\text { registered for catastrophic } \\
\text { illness }\end{array}$ & $\begin{array}{l}\text { Incident } \\
\text { (1-year } \\
\text { washout) }\end{array}$ & Yes & $\begin{array}{l}\text { Age, sex, index } \\
\text { year (frequency } \\
\text { matched) }\end{array}$ & $\begin{array}{l}\text { Age, sex, urbanisation, income, } \\
\text { comorbidity }\end{array}$ & 9 \\
\hline Zöller, $2012^{21}$ & $\begin{array}{l}\text { Population } \\
\text { based }\end{array}$ & $\begin{array}{l}\text { Any ICD code in inpatient } \\
\text { care }\end{array}$ & $\begin{array}{l}\text { Incident and } \\
\text { prevalent }\end{array}$ & Yes & None & $\begin{array}{l}\text { Age, sex, period, socioeconomic } \\
\text { status, region, comorbidity }\end{array}$ & 9 \\
\hline
\end{tabular}


stroke at the start of follow-up. ${ }^{9} 18$ Two studies did not adjust for any confounders or were unclear about adjustment. ${ }^{14} 18$ Six studies adjusted for history of cardiovascular disease, which is the strongest risk factor for stroke and none adjusted for antiphospholipid syndrome. Only three studies used ACR criteria to define SLE and the rest used ICD codes, ranging from liberal inclusion (one ICD code) to more stringent $(\geq 15$ SLE-coded visits).

There were four studies which used the Taiwan National Health Insurance Research Database (TNHIRD). ${ }^{14} 151720$ Liou et al and Wang et al both estimated the RR for overall stroke and had similar quality scores; therefore, we included Wang et al in analyses because they had a longer follow-up period. Three studies of similar quality used TNHIRD to estimate RRs for ischaemic stroke, and we included Chiu et al in our pooled analyses because they used a longer wash-out period. Two studies used TNHIRD for estimates of subarachnoid haemorrhage, and we included the study by Wang et al due to the higher quality score.

\section{RR for stroke}

The pooled RR for overall stroke was 2.53 (95\% CI 1.96 to 3.26), indicating that the risk of stroke in the SLE population is 2.5 times higher than the general population (figure 2). No significant heterogeneity was identified $\left(\mathrm{I}^{2}=23.0 \% ; \mathrm{p}=0.27\right)$. Restricting to the two inception cohort studies which excluded stroke at baseline and adjusted for comorbidities, ${ }^{16}{ }^{20}$ the RR was 2.89 (95\% CI 2.51 to 3.31 ).
The pooled RR for ischaemic stroke was 2.10 (95\% CI 1.68 to 2.62; figure 2). Removing the estimate from the study published only in abstract form at the time of this review, ${ }^{13}$ the pooled estimate was 2.11 (95\% CI 1.59 to $2.81)$. There was evidence of substantial heterogeneity that was statistically significant $\left(\mathrm{I}^{2}=79.2 \%, \mathrm{p}<0.002\right)$. Removing the study by Mok et al, ${ }^{18}$ which scored the lowest on the Newcastle-Ottawa scale, resulted in a pooled RR of 1.85 (95\% CI 1.62 to 2.12) and heterogeneity decreased $\left(I^{2}=47.9 \%, p=0.15\right)$. The pooled $R R$ from Asian studies was 2.43 (95\% CI 1.11 to $\left.5.32 ; \mathrm{I}^{2} 92.2 \%\right)$ compared to 1.98 in those studies not from Asia (95\% CI 1.75 to $2.25 ; \mathrm{I}^{2}=0.0 \%$ ).

The pooled RR for intracerebral haemorrhage was 2.72 (95\% CI 2.15 to 3.44 ), and the pooled RR for subarachnoid haemorrhage was 3.85 (95\% CI 3.20 to 4.64; figure 2). Removing Mok et al from the intracerebral haemorrhage estimate resulted in a similar estimate (RR 2.79; $95 \%$ CI 2.20 to 3.55 ). There was no evidence of heterogeneity for the intracerebral or subarachnoid haemorrhage outcomes $\left(\mathrm{I}^{2}=0.0 \%, \mathrm{p}=0.38\right.$; and $\mathrm{I}^{2}=0.0 \%$, $\mathrm{p}=0.44$, respectively), although this was based on small numbers.

Four studies stratified by age and reported stroke subtype-specific estimates, which are presented in figure 3, show that SLE was associated with the highest relative risk for stroke at younger ages. ${ }^{13} 182021$ Three studies also stratified RRs by sex and it appears that males and females do not have markedly different risks of stroke (figure 4). ${ }^{13}{ }^{20}{ }^{21}$ Liou et al ${ }^{17}$ stratified by steroid use and found that the risk of stroke was only

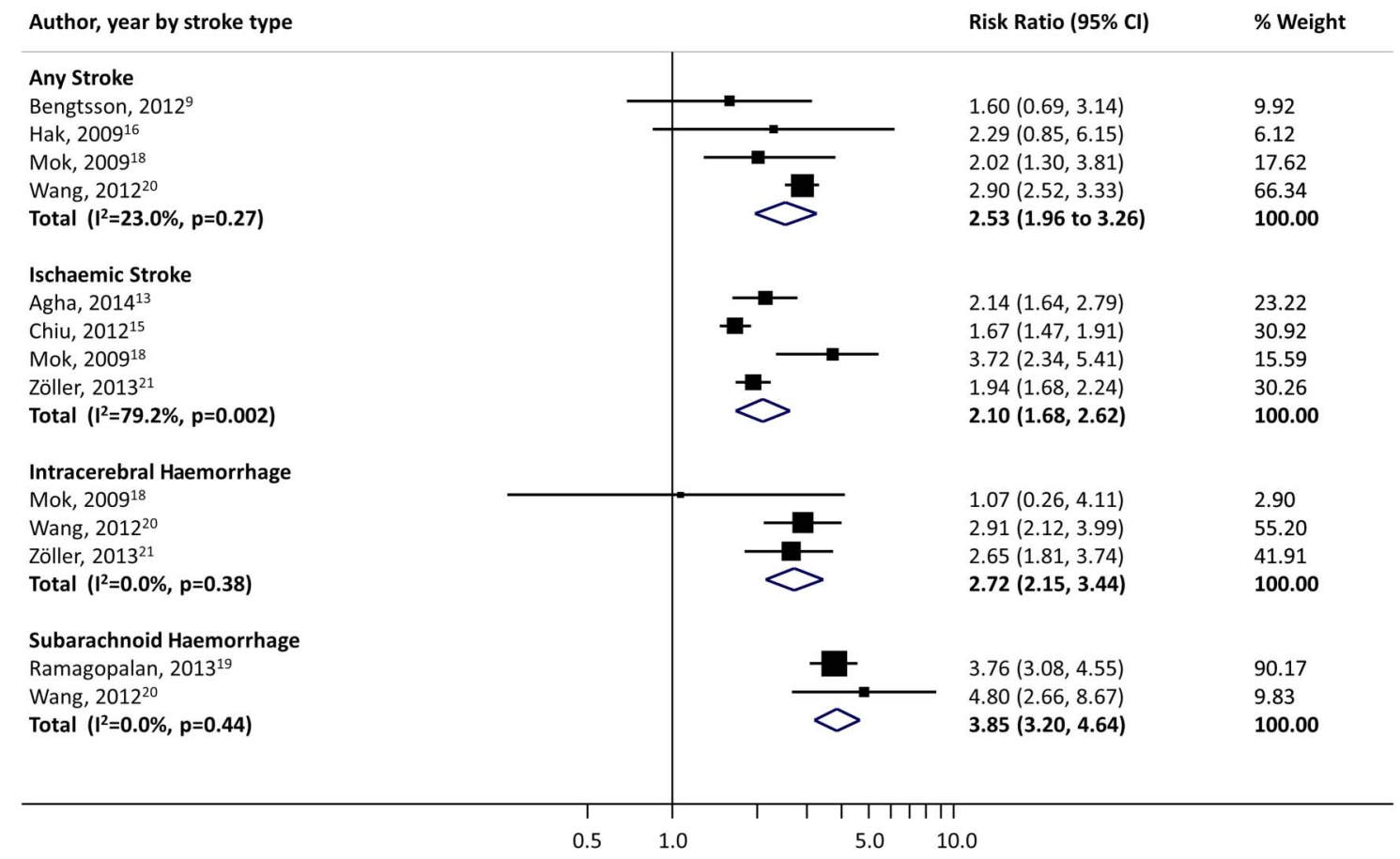

Risk ratio for stroke associated with SLE compared to the general population

Figure 2 Risk ratio for stroke overall, ischaemic stroke, intracerebral and subarachnoid haemorrhage associated with systemic lupus erythematosus (SLE). 


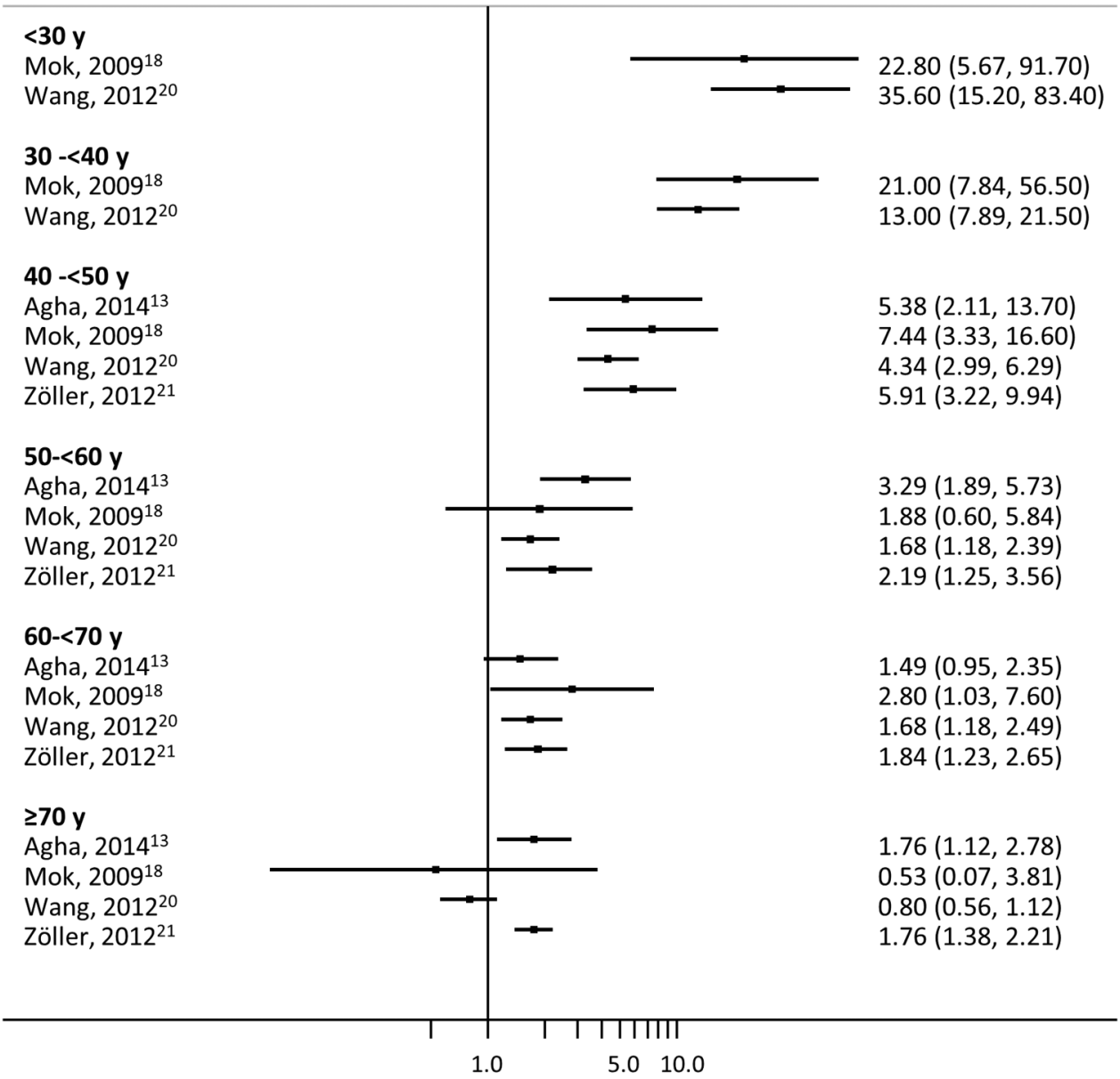

Risk ratio for stroke associated with SLE compared to the general population

Figure 3 Risk ratio for stroke associated with systemic lupus erythematosus (SLE) by age.

increased in patients with SLE who had concomitant steroid use. Wang et $a l^{20}$ was the only study which stratified RRs by several comorbidities (coronary artery disease, congestive heart failure, hypertension, diabetes, hyperlipidaemia, hypercoagulability, renal disease, atrial fibrillation and valvular heart disease). They reported
Figure 4 Risk ratio for stroke associated with systemic lupus erythematosus (SLE) by stroke type and sex.

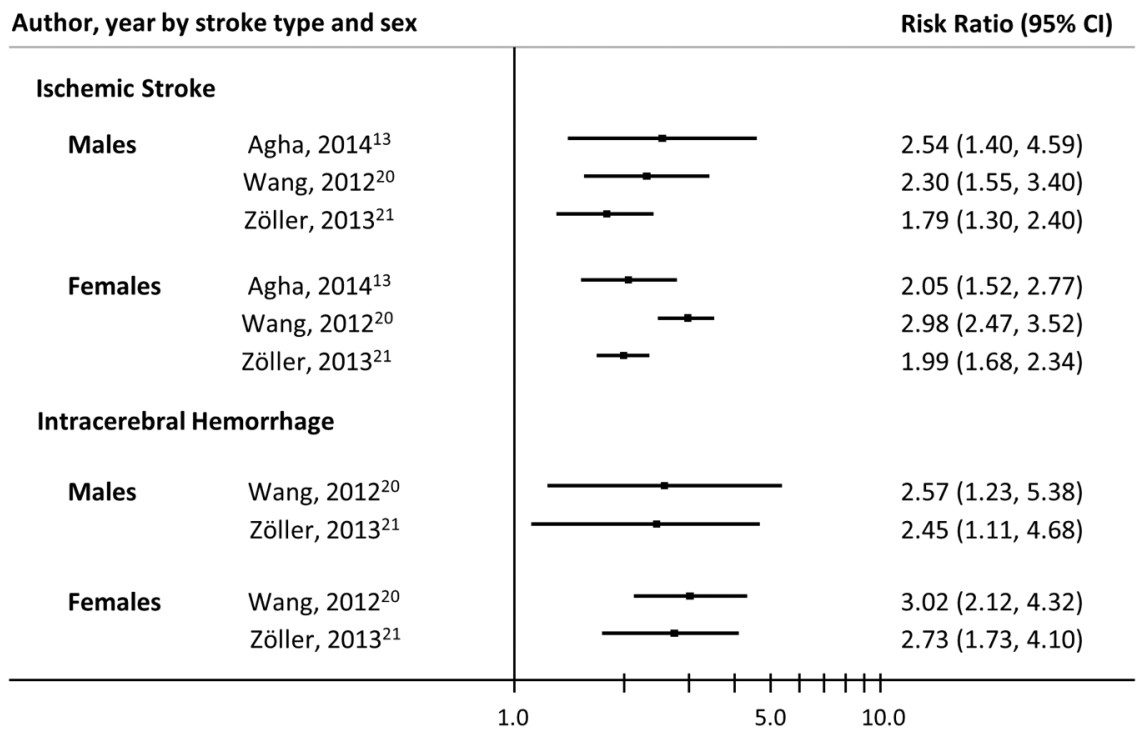

Risk ratio for stroke associated with SLE compared to the general population 
that the risk associated with SLE was higher in those without a history of these comorbidities, although these estimates were based on small numbers. Two studies examined RRs by follow-up time and found that the risk was highest in the first year after SLE diagnosis for intracerebral haemorrhage ${ }^{21}$ and subarachnoid haemorrhage. ${ }^{19}$

There was evidence of publication bias for the subset of studies which examined overall stroke (Egger's test $\mathrm{p}=0.04$ ) and the funnel plot showed asymmetry (there is a lack of small studies showing an increased risk of stroke; see online supplementary figure S1). For ischaemic stroke, intracerebral and subarachnoid haemorrhage subgroups, Egger's test $\mathrm{p}$ values were not significant $(\mathrm{p}=0.40,0.12$, and 0.08 , respectively). Influence analyses showed that no individual study appeared to greatly change the pooled RRs for each subtype of stroke.

To determine if the decision to exclude certain overlapping studies affected results, pooled RRs were calculated including those studies resulting in similar estimates (see online supplementary table S1).

\section{DISCUSSION}

We observed a twofold increased risk of ischaemic stroke and a threefold increased risk of intracerebral haemorrhage in individuals with SLE compared to the general population. The risk of subarachnoid haemorrhage was almost four times that of the general population. The increased ischaemic stroke risk may be attributed to several different causes. First, individuals with SLE have more comorbid conditions which are also risk factors for stroke such as vasculitis, antiphospholipid syndrome and hypertension. The highest relative risk of stroke was observed at younger ages, which may be partially explained by the accelerated and premature atherosclerosis seen in SLE. Furthermore, systemic inflammation may also play an important role in triggering stroke as has been seen in other chronic inflammatory diseases such as rheumatoid arthritis, polymyalgia rheumatica and chronic infections. ${ }^{29-31}$ Lastly, drug-related complications due to the immunosuppressive therapies often used in these patients could add to the risk. ${ }^{32}$

Other characteristics observed in SLE may contribute to the increased risk of thrombosis such as antiphospholipid syndrome, Libman Sacks endocarditis and immune deposits (eg, autoantibody-antigen complexes, lupus anticoagulant and antiphospholipid antibodies). The endothelial dysfunction seen in SLE may increase the likelihood of rupture, leading to haemorrhagic stroke. ${ }^{33-35}$

Intracranial vasculitis and hypertension may be responsible for the increased risk of subarachnoid haemorrhage. ${ }^{36}$ Our findings are different from those from a cross-sectional study which found that the odds for subarachnoid haemorrhage was decreased by $43 \%$ compared to the general population. ${ }^{3}$ Cross-sectional studies have generally reported lower RRs for stroke than cohort studies, likely due to the over-representation of healthier individuals and stroke survivors, which underestimates stroke prevalence. ${ }^{3}{ }^{5}$ This may be especially true in studies of subarachnoid haemorrhage which has a high mortality. ${ }^{37}$ It should be noted that the observed increased RR indicates that SLE is a risk factor for subarachnoid haemorrhage but the absolute risk may be quite low due to the event's infrequent occurrence.

Two studies, which lacked a general population comparator but estimated expected risks using the Framingham risk score, reported that SLE was associated with a sixfold to sevenfold increased risk. ${ }^{27}{ }^{28}$ Stroke risk estimates and scores reported in the literature differ substantially between each other, ${ }^{38}$ and the use of a risk score to estimate the general population's expected risk may not always yield an accurate comparison. Nevertheless, these studies highlighted that traditional risk factors are not as useful for predicting stroke risk in SLE. Patients with SLE have a unique constellation of characteristics which are rarely seen in the general population, such as antiphospholipid syndrome and vasculitis, indicating the need for awareness of SLE-specific risk factors for stroke.

Few studies presented estimates stratified by patient characteristics; these could shed light on which patients are at the highest risk of stroke and would benefit most from targeted prevention strategies. Two studies observed an increased risk of stroke in patients prescribed a steroid. ${ }^{14} 17$ This may indicate that during periods of flare and high disease activity, patients are especially vulnerable. Two studies also reported that individuals within 1 year of diagnosis were at the highest risk, which also may indicate a time period of poorly controlled disease. ${ }^{19} 21$

We observed a significant amount of heterogeneity in RRs for ischaemic stroke that decreased when the study by Mok et al was excluded. The differing results seen in Mok et al could be due to the inclusion of individuals with SLE who had been diagnosed with ACR criteria in a hospital-based clinic, compared to the other studies which used ICD codes from large administrative databases. Mok et al also differed in that they did not indicate whether SLE was prevalent or incident at the start of follow-up; also individuals with a history of stroke were not excluded and estimates were not adjusted for known confounders. There were several studies which used the Taiwan National Health Insurance Research Database, and two studies reported different estimates with CIs that did not overlap. ${ }^{15}{ }^{20}$ This may be due to differences in matching schemes or definitions of stroke. Depending on which studies from Taiwan were included in the pooled estimates for ischaemic stroke, we found RRs which ranged from 2.1 to 2.5 .

The small number of studies examining intracerebral and subarachnoid haemorrhage resulted in low power to detect heterogeneity in these subgroups. Most studies did not stratify by age, sex or comorbidity; therefore, we 
could not explore these variables as potential sources of heterogeneity. Owing to small numbers, we could not explore the effect of the length of disease duration and treatment on the development of stroke. These factors should be considered and evaluated in future cohort studies of stroke in SLE. Very few studies included stroke and/or SLE diagnoses obtained from medical record reviews, and instead relied on ICD codes; this could have caused misclassification of the exposure or outcome. There was evidence of publication bias for the studies examining overall stroke, which may have led to overestimation of the pooled RR. Despite these limitations, our study has several strengths. By pooling estimates from similar studies, we achieved increased power and improved precision to estimate stroke risk associated with a relatively rare risk factor. Restricting to studies that used a population-based comparator allowed us to estimate the risk of stroke associated with SLE, thus accounting for the underlying risks of stroke across different populations.

Not only are a number of strokes preventable, but damage and disability due to stroke can be minimised if identified early. Our results confirm that individuals with SLE are at a higher risk of stroke than the general population, regardless of the type of stroke. Future studies should focus on whether comorbidity and disease flares are related to stroke, when individuals are at the highest risk, and how targeting specific groups of patients with SLE may reduce this risk.

\section{Twitter Follow Elizabeth Arkema at @elizabetharkema}

Acknowledgements The authors would like to acknowledge J Antonio Avina-Zubieta, Christine Bengtsson and Solbritt Rantapää Dahlqvist for sharing unpublished data. They thank Susanne Gustafsson from the Karolinska Institute's library for providing consultation for our literature search.

Contributors MH, JFS and EVA designed the study. MH and EVA performed the literature search. EVA performed the analyses. KA provided methodological and clinical input. All authors interpreted the results, contributed to the writing of the manuscript and approved the final version.

Competing interests None declared.

Provenance and peer review Not commissioned; externally peer reviewed.

Data sharing statement Additional data may be provided on request.

Open Access This is an Open Access article distributed in accordance with the Creative Commons Attribution Non Commercial (CC BY-NC 4.0) license, which permits others to distribute, remix, adapt, build upon this work noncommercially, and license their derivative works on different terms, provided the original work is properly cited and the use is non-commercial. See: http:// creativecommons.org/licenses/by-nc/4.0/

\section{REFERENCES}

1. Cervera R, Khamashta MA, Font $\mathrm{J}$, et al. Morbidity and mortality in systemic lupus erythematosus during a 10 -year period: a comparison of early and late manifestations in a cohort of 1,000 patients. Medicine (Baltimore) 2003:82:299-308.

2. Yurkovich M, Vostretsova K, Chen W, et al. Overall and cause-specific mortality in patients with systemic lupus erythematosus: a meta-analysis of observational studies. Arthritis Care Res (Hoboken) 2014;66:608-16.
3. Krishnan E. Stroke subtypes among young patients with systemic lupus erythematosus. Am J Med 2005;118:1415.

4. Ward MM. Outcomes of hospitalizations for myocardial infarctions and cerebrovascular accidents in patients with systemic lupus erythematosus. Arthritis Rheum 2004;50:3170-6.

5. Ward MM. Premature morbidity from cardiovascular and cerebrovascular diseases in women with systemic lupus erythematosus. Arthritis Rheum 1999;42:338-46.

6. Saadatnia M, Sayed-Bonakdar Z, Mohammad-Sharifi G, et al. Prevalence and prognosis of cerebrovascular accidents and its subtypes among patients with systemic lupus erythematosus in Isfahan, Iran: a hospital clinic-based study. Int J Prev Med 2014;5:123-6.

7. Bessant R, Hingorani A, Patel L, et al. Risk of coronary heart disease and stroke in a large British cohort of patients with systemic lupus erythematosus. Rheumatology (Oxford) 2004;43: 924-9.

8. Bartels CM, Buhr KA, Goldberg JW, et al. Mortality and cardiovascular burden of systemic lupus erythematosus in a US population-based cohort. J Rheumatol 2014;41:680-7.

9. Bengtsson C, Ohman ML, Nived O, et al. Cardiovascular event in systemic lupus erythematosus in northern Sweden: incidence and predictors in a 7-year follow-up study. Lupus 2012;21:452-9.

10. Feigin VL, Lawes CM, Bennett DA, et al. Worldwide stroke incidence and early case fatality reported in 56 population-based studies: a systematic review. Lancet Neurol 2009;8:355-69.

11. Moher D, Liberati A, Tetzlaff J, et al. Preferred reporting items for systematic reviews and meta-analyses: the PRISMA statement. $J$ Clin Epidemiol 2009;62:1006-12.

12. Wells GA, Shea B, O'Connell D, et al. The Newcastle-Ottawa Scale (NOS) for assessing the quality of nonrandomised studies in meta-analyses (cited 26 March 2015). : http://www.ohri.ca/programs/ clinical_epidemiology/oxford.asp

13. Agha M, Esdaile J, Yurkovich M, et al. Risk of cerebrovascular accidents in patients with systemic lupus erythematosus: a population-based study. J Rheumatol 2014:41:1439.

14. Chang YS, Liu CJ, Chen WS, et al. Increased risk of subarachnoid hemorrhage in patients with systemic lupus erythematosus: a nationwide population-based study. Arthritis Care Res 2013:65:601-6.

15. Chiu CC, Huang CC, Chan WL, et al. Increased risk of ischemic stroke in patients with systemic lupus erythematosus: a nationwide population-based study. Intern Med 2012;51:17-21.

16. Hak AE, Karlson EW, Feskanich D, et al. Systemic lupus erythematosus and the risk of cardiovascular disease: results from the nurses' health study. Arthritis Rheum 2009;61:1396-402.

17. Liou TH, Huang SW, Lin JW, et al. Risk of stroke in patients with rheumatism: a nationwide longitudinal population-based study. Sci Rep 2014;4:5110.

18. Mok CC, Ho LY, To CH. Annual incidence and standardized incidence ratio of cerebrovascular accidents in patients with systemic lupus erythematosus. Scand J Rheumatol 2009;38:362-8.

19. Ramagopalan SV, Pakpoor J, Seminog O, et al. Risk of subarachnoid haemorrhage in people admitted to hospital with selected immune-mediated diseases: record-linkage studies. BMC Neurol 2013;13:176.

20. Wang IK, Muo $\mathrm{CH}$, Chang YC, et al. Risks, subtypes, and hospitalization costs of stroke among patients with systemic lupus erythematosus: a retrospective cohort study in Taiwan. $J$ Rheumatol 2012;39:1611-18.

21. Zöller B, Li X, Sundquist $\mathrm{J}$, et al. Risk of subsequent ischemic and hemorrhagic stroke in patients hospitalized for immune-mediated diseases: a nationwide follow-up study from Sweden. BMC Neurol 2012;12:41.

22. James $A H$, Bushnell $C D$, Jamison MG, et al. Incidence and risk factors for stroke in pregnancy and the puerperium. Obstet Gynecol 2005;106:509-16.

23. Soh MC, Nelson-Piercy C, Dib F, et al. Association between pregnancy outcomes and cardiovascular deaths in women with systemic lupus erythematousus utilising Swedish population registries. Arthritis Rheumatol 2015;67:2376-82.

24. Mustonen $\mathrm{P}$, Lehtonen KV, Javela K, et al. Persistent antiphospholipid antibody (aPL) in asymptomatic carriers as a risk factor for future thrombotic events: a nationwide prospective study. Lupus 2014;23:1468-76.

25. Lin JA, Liao CC, Lee YJ, et al. Adverse outcomes after major surgery in patients with systemic lupus erythematosus: a nationwide population-based study. Ann Rheum Dis 2014;73:1646-51.

26. Ward MM. Cardiovascular and cerebrovascular morbidity and mortality among women with end-stage renal disease attributable to lupus nephritis. Am J Kidney Dis 2000;36:516-25. 
27. Esdaile JM, Abrahamowicz M, Grodzicky T, et al. Traditional Framingham risk factors fail to fully account for accelerated atherosclerosis in systemic lupus erythematosus. Arthritis Rheum 2001:44:2331-7.

28. Magder LS, Petri M. Incidence of and risk factors for adverse cardiovascular events among patients with systemic lupus erythematosus. Am J Epidemiol 2012;176:708-19.

29. Holmqvist M, Gränsmark E, Mantel A, et al. Occurrence and relative risk of stroke in incident and prevalent contemporary rheumatoid arthritis. Ann Rheum Dis 2013;72:541-6.

30. Hancock AT, Mallen CD, Muller S, et al. Risk of vascular events in patients with polymyalgia rheumatica. CMAJ 2014;186:E495-501.

31. Grau AJ, Urbanek C, Palm F. Common infections and the risk of stroke. Nat Rev Neurol 2010;6:681-94.

32. Ruyssen-Witrand A, Fautrel B, Saraux A, et al. Cardiovascular risk induced by low-dose corticosteroids in rheumatoid arthritis: a systematic literature review. Joint Bone Spine 2011;78:23-30.
33. Gustafsson J, Gunnarsson I, Börjesson O, et al. Predictors of the first cardiovascular event in patients with systemic lupus erythematosusa prospective cohort study. Arthritis Res Ther 2009;11:R186.

34. Bertsias GK, Salmon JE, Boumpas DT. Therapeutic opportunities in systemic lupus erythematosus: state of the art and prospects for the new decade. Ann Rheum Dis 2010;69:1603-11.

35. Fayyaz A, Igoe A, Kurien BT, et al. Haematological manifestations of lupus. Lupus Sci Med 2015;2:e000078.

36. Feigin VL, Rinkel GJ, Lawes CM, et al. Risk factors for subarachnoid hemorrhage: an updated systematic review of epidemiological studies. Stroke 2005;36:2773-80.

37. van Gijn J, Kerr RS, Rinkel GJ. Subarachnoid haemorrhage. Lancet 2007;369:306-18.

38. Asplund K, Karvanen J, Giampaoli S, et al. Relative risks for stroke by age, sex, and population based on follow-up of 18 European populations in the MORGAM Project. Stroke 2009;40:2319-26. 